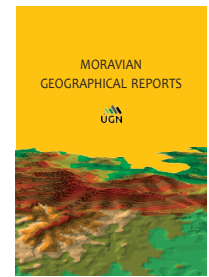

MORAVIAN GEOGRAPHICAL REPORTS

The Czech Academy of Sciences, Institute of Geonics

journal homepage: http://www.geonika.cz/mgr.html

doi: https://oi.org/10.2478/mgr-2021-0001

\title{
Decoding escape rooms from a tourism perspective: A global scale analysis
}

\author{
Arsenio VILLAR LAMA ${ }^{\text {* }}$, Miguel GARCÍA MARTÍN ${ }^{\text {b }}$
}

\begin{abstract}
There has been a spectacular growth in the escape game sector over the past decade. The extraordinary global impact of escape rooms, their implications for tourism, and the limited literature provide grounds for this research. This paper examines such phenomena using an empirical methodology based on a geographic analysis of business repositories and a global survey. Tourism plays a significant role in the escape room industry: approximately one of every three customers is a tourist. Escape roomer-tourists have even been detected: people who essentially plan their trips with the sole intention of playing these games. A significant contrast exists between business-owners and countries, however, as to the role given to foreign customers and the opportunities that all the above implies. Indeed, the connection between escape room narratives and the local culture has been shown to be weak in a majority of cases. Thus, this contribution seeks to feed into an emerging and increasingly relevant debate that has been little addressed in tourism geography: linking experiences, creative economies, authenticity and cultural heritage, etc. - through escape rooms.
\end{abstract}

Keywords: escape games, recreation, tourist experience, authenticity, cultural landscape

Article history: Received 30 April 2020, Accepted 20 October 2020, Published 31 March 2021

\section{Introduction}

"In China, people are paying $\$ 13$ to be locked in a room and forced to solve puzzles to get out": this December 2013 headline from The Verge (Jeffries, 2013) described a report on the first escape rooms in Beijing in The Wall Street Journal. Regarded as a descendant of Japanese Takagism ${ }^{1}$ in East Asia, this leisure segment is beginning to flourish worldwide and a variety of precursors have been identified (Nicholson, 2015). When this report asked subscribers to comment, they described similar patterns in a variety of cities around the world.

An escape experience is an immersive team-based game, the objective of which is to escape from a room within a given time. The challenge usually involves not just escaping from the room but also a story with a specific goal: finding a treasure, stealing something, finding a key, thwarting a programmed terrorist threat, etc. The room is full of objects and clues that have to be solved. Some elements are accessories and others are relevant for making progress: keys or data that open safes, briefcases, drawers, cabinets or even doors that allow access to additional unexpected rooms. The environments are varied: a cell, an apartment, a warehouse, a bank, a rail car, an asylum, a laboratory... sometimes a recreation of the past, such as a pirate ship, an Egyptian pyramid, a medieval hall or a Second World War bunker.

The leisure economy is expanding, diversifying and becoming more professional in response to the growing demand for recreation. After commodities and goods and services, experiences - as the fourth stage of Economic Value - have flourished spectacularly: "experiences are not an amorphous construct; it is as real an offering as any service, good, or commodity" (Pine and Gilmore, 1999, p. 98). In this context, and in part due to the rapid development of technologies in everyday life (virtual relations, the digital society, etc.), the experience industry has to all appearances been revamped and reinvigorated by a new generation

\footnotetext{
${ }^{a}$ Department of Physical Geography and Regional Geographic Analysis, University of Seville, Spain (*corresponding author: A. Villar Lama, e-mail: arsenio@us.es)

${ }^{\mathrm{b}}$ Department of Human Geography, University of Seville, Spain
}

\footnotetext{
1 Toshimitsu Takagi is a Japanese multimedia and game developer which created "Crimson Room" in 2004. This and "The Mystery of Time and Space", developed by Jan Albartus in 2003, are usually considered to be the virtual forerunners of real escape games
} 
of offline entertainment, such as climbing walls, military games (paintball), street gymkhanas and - one of the latest phenomena round the world (Stasiak, 2016) - escape rooms. As an experience product, escape rooms possess the basic ingredients of a structured experience (Ellis et al., 2019): play, immersion, mindfulness, absorption, engagement and quality. Kolar (2017) also identifies novelty and authenticity as basic components of the experience in these escape attractions. Mitas and Bastiaansen (2018) discuss the relevance of novelty - experiencing something new and different than the day to day, believed to be enjoyable - for explaining tourists' positive emotions. In contrast, Wang (1999) draws a distinction between the authenticity of objects, the authenticity of experiences, and existential authenticity. Escape games might be an authentic form of termed constructed experience and could mediate a tourism experience in positive emotions.

Although one precedent can be traced back to the first decade of the $21^{\text {st }}$ century (Nicholson, 2015), the business first emerged in its current format toward the early 2010s and has seen extraordinary growth in recent years. According to Spira (2019), the number of companies in the United States has increased from two dozen facilities in 2014 to 2,300 in 2019. Meanwhile, in Europe, if we take Spain as an example, according to the Escape Room Lover blog in 2019, the business has ballooned $451 \%$, from 150 companies in mid-2016 to 677 in 2019 and 958 in 2021. The rapid development of the offer has been accompanied by the extraordinary popularity of this new form of recreation: escape facilities are ranked among the top "things to do" in the biggest cities around the world in TripAdvisor's What to do indoors? lists. As such, there is a need for a deeper understanding of the phenomenon.

The emerging nature of the sector and its spread around the globe, its implications for tourism, and the limited previous scientific literature all justify the present contribution. This is one of the first papers to systematically examine the geographic features of these attractions, and to contribute to the understanding of escape rooms from the scope of the offer. Specifically, the authors present an analysis of general patterns - dimensions, evolution and location, a deep characterization of the sector and a discussion of its role in contemporary hospitality and tourism. For such purposes, the paper is structured as follows: first, the main concepts and ideas are addressed through a review of the limited literature on escape rooms and their implications for tourism. Second, the sources and methodology are described. Next, the results are presented and discussed. Finally, the conclusions are highlighted.

\section{Literature review}

Despite their impact in the media, little scientific literature exists today on escape rooms ${ }^{2}$. Most of the contributions are focused on the use of escape experiences for didactic purposes, particularly team building and active learning from Primary School to Higher Education. The growing acceptance of escape rooms as entertainment and the popularity of educational games have led teachers to repurpose these experiences for the classroom. In this respect, the first studies on the topic have shown a positive impact on content knowledge and collaboration skills. In education, escape challenges have been tested by a wide range of individuals from children (see Nicholson, 2018) to university students, especially in the medical sciences (Kinio et al., 2017), chemistry (Dietrich, 2018) and engineering (Borrego et al., 2017). A few other contributions have drawn attention to such varied fields as librarianship - in order to promote reading, literacy, and search skills (Wise et al., 2018), language learning (Dorado, 2018), and technical writing (Melo and Johnson, 2018).

Despite focusing on the educational field, in his "Peeking behind the locked door", Nicholson (2015) is the first author to systematise the origins of the sector and to give an approach to the characteristics of the offer, especially in the United States. In this regard, this author includes some questions that have strong links to the goals of the present research, such as perceptions of the market, narratives and local culture.

Escape rooms are one of the latest phenomena in the leisure market. Leisure, recreation and tourism generally are seen as a set of interrelated and overlapping concepts. Following Hall and Page (2014), tourism and recreation are generally regarded as subsets of the wider concept of leisure, and due to this overlap, broader approaches ensure more powerful explanations: "This is because society is not divided into sports players, television viewers, tourists and so on. It is the same people who do all these things" (ibid., p. 8). As a leisure service, in escape rooms - recreational, tourist and work experiences converge. This work assumes these intersections and starts from a holistic conception, but further analyses the implications of escape rooms for tourism.

Research in the social sciences into the impact of escape rooms on leisure is still in its nascent stages and few contributions have been published to date ${ }^{3}$. Most of these studies have focused on their recreational role, from both the supply and demand perspectives. Stasiak's (2016) and Villar's (2018) works are geographically-driven, describing how the sector spread to Poland and Spain respectively. Stasiak (2016) systematises the origin and structure of these games and also some location patterns at the urban scale in ten Polish cities, while Villar (2018) - in a similar historical overview - surveys Spanish entrepreneurs to give a profile of the offer and initiates what might be called a basic "Geography of Escape Rooms". These contributions both show the remarkable growth of the sector, its major relationships with recreation, and its special impact on the millennial generation. For their part (demandled approaches), Kolar (2017), Kolar and Čater (2018), Dilek and Dilek (2018), and Stasiak (2019) analyse users' experiences using etnography techniques. In these cases, the study area takes a second place and the phenomenon is contextualised within hospitality research as novelty experiences, post-modern tourism and the management of flows. These academic researchers generate a complete discussion of these activities from the perspective of demand, highlighting the way that these attractions provide new,

\footnotetext{
${ }^{2}$ A literature search was conducted on Scopus and the Web of Science academic databases. A total of 80 documents were retrieved using the term "escape room" in both cases. A detailed exploration shows a temporal concentration since 2017 (75 entries), with no results prior to 2015. A similar pattern was seen in an examination of Google Scholar, a broader-focus browser, with only 1,880 results $(1,430$ since 2015$)$.

${ }^{3}$ A finer search leads to only 9 papers that analyse escape rooms from social science subject perspectives such as hospitality management, tourism studies and geography.
} 
peak, unique and fan experiences through the challenging social components of gameplay (Kolar, 2017), the importance of theming, narratives and word-of-mouth communication for management purposes (Kolar and Čater, 2018) and, lastly, a comprehensive description of users (motivations, frequency, emotions, etc., see Stasiak, 2019).

These contributions are only partially aware of the implications of this business for tourism: for example, Nagy, Petykó, Diána and Egedy (2018), and Bakhsheshi (2019), have analysed escape rooms as innovative tourist products. The first of these two studies discusses the case of Budapest in the context of creative tourism. The authors underline the innovativeness and creativity of local entrepreneurs as a kind of tipping point for certain destinations, in coherence with the new intangible resources in travel economies such as lifestyles, atmospheres, narratives and media (Richards, 2009). The second study proposes the activity as a novel and memorable experience for tourists. In this sense, we understand that escape rooms are suitable laboratories to study the role of authenticity in leisure industries, as manufactured products linked to residents' and travellers' experiences. The role of the design of spaces in leisure research often focuses on generating places for recreational use, as largely physical places the foundation on which experience is built, designed and valued. The generation of an escape-room tourist destination (e.g. Barcelona) leads to stimulating questions about tourist authenticity (following Rickly and McCabe, 2017): can we truly design spaces for authentic engagement? Is it ever possible to authentically experience places that have been designed?

Multiple theoretical approaches to authenticity have been taken in tourism and leisure studies (Rickly, 2013): from objective views (Lau, 2010), where authenticity is seen as the genuineness of a certain artifact, structure or ritual, measured by experts; to constructivist perspectives that contend that tourists look for symbolic authenticity rather than essentialist properties. These object-based approaches were deconstructed by Wang (1999, p. 358) - as objectoriented perspectives present conflicting points of view regarding tourist motivations and experiences in relation to the epistemological understandings of the object being visited - arguing that "a postmodernist deconstruction of the authenticity of the original implicitly paves the way to defining existential authenticity as an alternative experience." This existential authenticity ties in with the two dimensions of the studied phenomenon: the intrapersonal dimension implies bodily sensations (Cook, 2010) and/or self-making experiences (Kim and Jamal, 2007), while an interpersonal dimension ties in with a sense of communitas (Rickly, 2013). Some authors (Nicholson, 2015; Kolar, 2017; Dilek and Dilek, 2018) have identified escape rooms as flow experiences (Csikszentmihalyi, 1990), in which a group of people plays in a coordinated fashion with the same objective, everyone is fully immersed, and some essential elements of a tourist experience - emotional, learning, practical and transformational - are present (Bakhsheshi, 2019; Bakhsheshi and Ghaziani, 2019).

Finally, apart from the scientific literature, marketing and consulting agencies have used surveys of business owners to develop inventories and technical reports (state of the industry) (Agarwal, 2018; Sofmarr LLC, 2018). Although they mostly focus their attention on aspects that fall outside the scope of this research project, such as the creation of the game and the business, maintenance and security systems, other features that are more relevant for our topic are included, such as the entrepreneur profile, player demographics and themes. The previous scientific literature and such technical reports are discussed below in concert with the main findings of our investigation.

This phenomenon is thus garnering growing attention both inside and outside the academic world. Nevertheless, there are many focal issues that are still unexplored. In this respect, the implications of escape games for tourism enable us to dig deeper, especially into the relationship between the activity as a tourist offering, on the one hand, and the destination as a well-known, well-represented and symbolised place. In this sense, tourism geography has highlighted the qualities and significance that societies place on their lands, which leads us to a landscape conception of the tourist destination (Cartier, 2005; Crouch, 2013). Escape rooms, especially those that, as will be seen below, are designed to take the city or region in which they are located into consideration, transfer to and confer upon the game plot, the qualities and attributes that most and best characterise the area. This is a mechanism that both qualifies the product and affords it some distinctiveness in a highly competitive market (Pritchard and Morgan, 2001; Truong et al., 2018). In addition, it should not be forgotten that these entrepreneurs can exploit core topics and consolidated tourist routes to make themselves more visible in the complementary tourist market.

\section{Data and methods}

An exploratory geographical study has been conducted to gain an insight into the escape room sector. A survey was selected as the research method as it has the ability to be administered to every facility in the world quickly and at low cost via the Internet (Solomon, 2001; Gunn, 2002). The first step in such a survey is to define the research universe. The present study is focused on escape facilities and does not include any other agents such as designers, bloggers or demand factors. Identification of the offer allows both the market distribution to be identified and a list of contacts to be obtained for the survey. The primary sources were two company directories: the Escape Room Directory (ERD, 2017) and Escape the RoomZ by Sofmarr LLC (2018).

The challenge of determining the size of the phenomenon at the global scale is complicated due to the poor availability of international directories, their bias toward certain countries and their infrequent updating. Although intermediation websites and escaper blogs have been developed, they are country-based and only list the national offers. The previous research (Stasiak, 2016; Villar, 2018) used ERD to obtain an international perspective, but this directory is no longer updated: the latest version (August 2017) contained over 2,500 registered facilities and 7,000 rooms ${ }^{4}$. A yearbook with a new listing was published in December 2018 by Sofmarr LLC, a company focused on escape room-related information, products and services, according to which about 5,736 enterprises currently operate worldwide. Both indexes were tested at certain locations using national

\footnotetext{
${ }^{4}$ As its webmaster explained in a personal communication, it was not possible to achieve perfect coverage in any given place, so this is almost certainly an underestimate of the number of rooms in the world, especially since there were basically no East Asian rooms represented.
} 
directories, Google Maps and TripAdvisor ("Escape Room Barcelona", "Escape Game Moscow", "Escape Game Sydney", etc.). These sources have proved valuable on account of their spatial coverage, although misrepresentations have been detected in certain countries such as Russia, Japan, South Korea and, especially, China. In this regard, there is a noticeable lack of accurate information to obtain an overall picture of the phenomenon in the Chinese market, which is almost certainly the leading market in the world (Nagy et al., 2018). Some corporate organisations put the total number of escape rooms in China at more than 4,000 in 2018 (China EGA, 2020). Nevertheless, this figure contrasts with the scarcity of Chinese companies registered in the many directories that can be consulted, making this obstacle one of the main limitations of our research design. Thus, the main results and conclusions of our work might be extended to most of the world, as revealing a global phenomenon, but all the while bearing in mind this unavoidable underrepresentation with respect to China

As these directories only provide the URLs of the facilities, an automated bulk e-mail finder was run using Hunter.io software. A total of 8,468 e-mail addresses were extracted: 2,849 from ERD and 5,619 from Sofmarr LLC. The two lists were combined to ensure the maximum scope of the survey. After this, duplicate rows had been eliminated and a final total of 6,441 e-mail addresses in 117 countries was obtained for use as a contact list.

Once the global offer was quantified and mapped by country, a 20-questions in 3 sections survey was designed:

1. Business and owner profile: year of opening, number and age of business partners, number of employees, franchises, relations with competitors, etc.;

2. Tourism implications: percentage of tourists, number of languages spoken, promotion at hotels and tourist attractions, etc.; and

3. Importance of theme and place: relationship between the room's theme and the place (city/region), outdoor games offer, location patterns, etc.

A total of 356 responses were obtained from 50 countries and approximately 270 cities. In addition to these numbers, 70 respondents filled out a final open query (Other comments and suggestions) that provided useful qualitative information. Although this sample is statistically significant over our universe of 6,441 escape rooms, the underrepresentation of China in repositories does not allow establishing definitive findings in the matter ${ }^{5}$. A content analysis was carried out for a better understanding of the results. This methodological procedure is useful for reducing all the information provided by respondents to a smaller number of categories, using explicit coding rules and controlled and interpretive deduction through semantic inference (Bardin, 1977; Weber, 1990, Schreier, 2012; Krippendorff, 2013).

There are no records of ER entrants that contain customer data, especially regarding their place of origin. As stated by Nagy et al. (2018), databases allow a demand analysis, and service owners rarely include information about the type of customer, making a fine distinction between locals, travellers and tourists impossible. Our survey is based on the providers' perceptions (on a scale of 0-10) of the relative proportion of non-locals. This has a bearing on the accuracy of data on the percentage of tourists intended to complement other indexes (number of languages, promotion of tourism facilities, etc.), to determine the importance of tourism in this type of business. The final open question has also provided us with some further information in this regard, as will be seen below.

The procedure and the subsequent results responded to the following research questions:

- Q1: What are the global numbers and the distribution of this phenomenon?;

- Q2: What are the business models and the entrepreneur profiles?;

- Q3: To what extent is tourism present in this industry? Do managers identify the tourism opportunities of their facilities?; and

- Q4: To what extent are local culture and distinctive heritage incorporated into the design of the game's storyline? If so, is it possible to align a designed space with an authentic form of tourism experience?

\section{Results and discussion}

\subsection{Global numbers}

According to Sofmarr LLC (2018), which is the more accurate and more up-to-date of the two directories, a total of 5,740 facilities are registered in 117 countries. Wójcik and Multan (2020) present a total figure of 8,000 - which has not been rigorously verified - which might cover China and Japan. Apart from with the underestimated Asian market, the phenomenon is clearly located in Europe $(2,789)$ and North America (USA and Canada, 2,426) (see Fig. 1). In Europe, Spain, the United Kingdom, Netherlands, Germany, France, Italy and Poland have more than 200 companies each. By virtue of their clear leading position in the region, these countries are hereafter referred to as the "Big7". The great expansion in Spain is confirmed: Villar (2018) counted 275 escape rooms in March 2017, whereas today it is the second-largest market in the world. The growth in popularity of the sector in Poland identified by Stasiak (2016) is also validated. Apart from these prevailing areas, Australia, India, Israel, Malaysia, and New Zealand should be highlighted as secondary markets (between 100 and 25 facilities, respectively).

The sector is in its nascent stages in South America with escape rooms currently being opened throughout the entire region. Brazil is the current leading country, but with only 21 . Nevertheless, growth is especially intense in major cities (Sao Paulo, Rio de Janeiro, Buenos Aires and Santiago) where using national directories and Google Maps - new rooms are opening every month and international directories are likely to become obsolete in the immediate future. Similarly, in Africa, the phenomenon has just reached countries such as Egypt, South Africa and Nigeria (between 15 and 5 facilities) and is starting to spread in some cities.

The use of a weighting coefficient shows the relationship between the offer and the local demand and might be useful for estimating the sector's popularity. A similar index used by Stasiak (2015) for the main Polish cities is given in Figure 1. The ratio is particularly high (more than 8 facilities per million inhabitants) in Europe, where the Netherlands, Finland, Spain, Estonia, and Cyprus stand out. Some other European countries (Greece, Switzerland, Slovenia, Latvia, Poland, amongst others) are on a second

\footnotetext{
${ }^{5}$ Our sample has statistical significance at a 95\% confidence level and with a $5 \%$ error rate.
} 


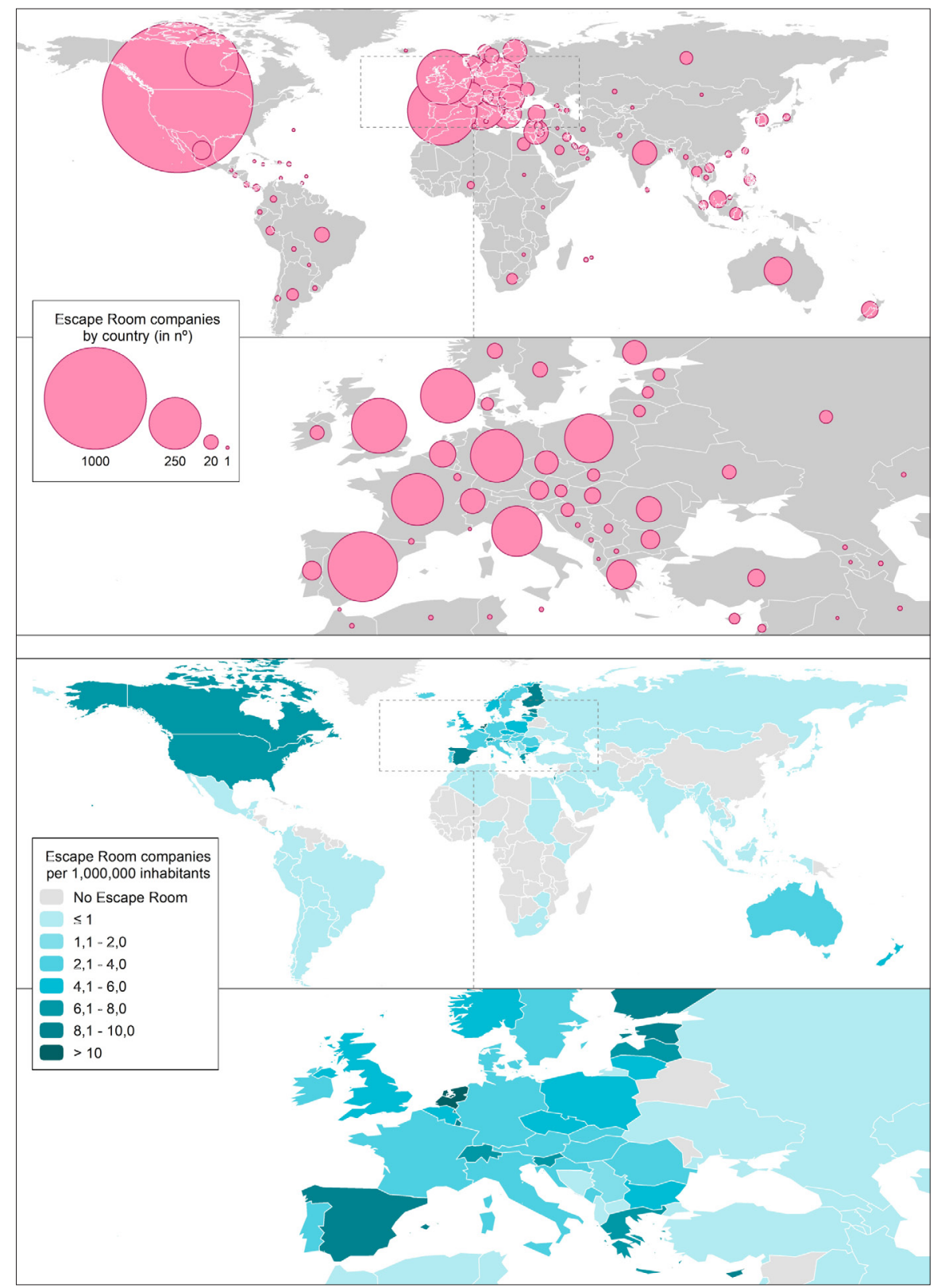

Fig. 1: Global distribution of escape rooms

Source: Prepared by authors from Sofmarr LLC (2018)

tier (5 to 8 companies per million), along with Canada and the United States. Market distribution is uneven and there seems to be no global pattern that explains distribution by country. On a national scale, some authors (Stasiak, 2016; Villar, 2018) have already highlighted prior development in the largest urban areas and the subsequent expansion to small cities, coastal destinations and towns. As a single-use business - the customer is won and lost at the same time expansion is linked to well-populated and most visited cities, where popularity and novelty among locals and tourists have led businesses to seek promotion. According to Kowalik (2015), these facilities may function well in cities inhabited by at least 100,000 people. Such a study is not within the scope of this paper, but a deeper small-scale analysis might contribute to understanding the geographical drivers of the phenomenon at the regional and national scales. These data are available in Appendix 1.

According to our survey data, this leisure industry boomed around 2016: almost 3 of every 4 respondents (72\%) opened their businesses during the 2015-2017 period, with 2016 the peak year for almost one third of the total sample (Fig. 2). This pattern can be verified in the consulted literature: French and Shaw (2015) describe the explosive growth of the sector worldwide during the 2010-2015 period, from zero at the beginning of 2010 to at least 2,800 in 2015, according to MarketWatch calculations.

Our data reflect the decline in new openings but does not include closures: in line with Spira (2019), 1 every 3 US companies have closed in the 2014-2019 period, with 2018 and 2019 the years with the highest number of closures $(86 \%$ of total). Some experts predict a reduction in the number of facilities due to the new customer segment 'drying up' (Stasiak, 2019). Also, the possible effect of COVID-19 on the leisure and tourism industries in general, and escape rooms, in particular, might reduce the offer - the business contravenes the established principles for tackling the virus as it is fundamentally based on a group of people handling objects in a locked room with no ventilation - or the adaptation of a real game to a virtual setting (Bass, 2020; Meszaros, 2020; Roe, 2020), which can be understood as a return of escape 


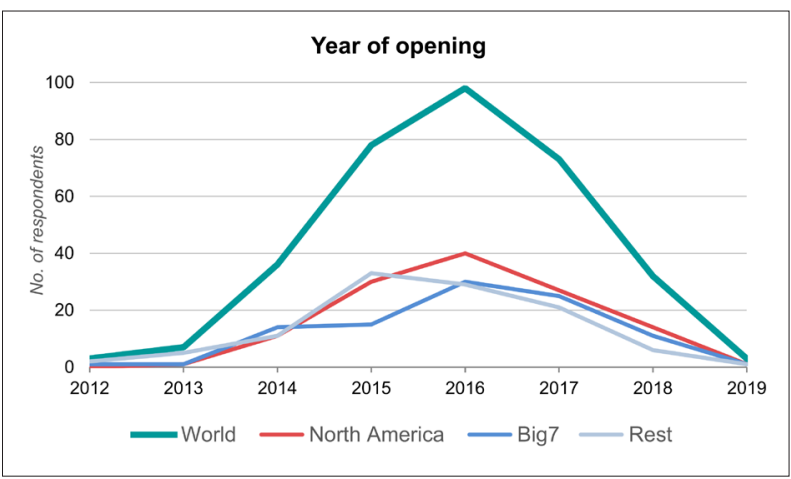

Fig. 2: Number of businesses opening by year Source: authors' survey and processing

rooms to their digital origins and, in the final instance, a loss of their greatest appeal (handling objects, physical contact, exercise, disconnection from the virtual world, etc.).

\subsection{Business and entrepreneur profiles}

According to our survey, $72 \%$ of the companies are owned by one or two partners. Based on a cross-tabulation, we don't find interregional differences at this regard. As commented by survey respondents - and noted by other authors (Agarwal, 2018; Villar, 2018) - the existence of a family link is very common. For $60 \%$ of the respondents, it is their main business, while for $40 \%$ it is a complementary activity. The average age of the entrepreneur is 38.1 years. Almost one third of all the entrepreneurs are in their thirties. In the United States, the average age is higher and more broadly distributed among different cohorts. The age of partners and players - see Nicholson (2015) and Agarwal (2018) - leads us to regard escape rooms as an activity strongly linked to the millennial generation.

The sector is primarily based on micro and small enterprises. French and Shaw (2015) underlined the role of smaller businesses, each operating in a single city or region, with some run by enthusiasts who saw the trend taking off and decided to strike out on their own, as noted by one respondent: "Escape games have become my fulltime profession. As a backgrounder [sic] I was in training and development for a global research and development pharmaceutical company and also worked in sales leadership. I left the corporate environment to pursue my own company" (respondent No. 178). The number of people hired varies greatly: $11 \%$ are self-run, while $56 \%$ employ 5 or more people. This pattern is in line with previous research (Agarwal, 2018), which shows that, as escape games continue to grow, they will become a reliable and more recognised source of career opportunities. The cross tabulation shows that this is particularly applicable in North America - where escape rooms have higher employability ( $71 \%$ employ 5 or more) - while in the Big7 countries 53\% operate with fewer than 5 people and a significant $14 \%$ are personal or family operations. Self-management is especially relevant (25\%) in some countries, such as Spain.

Escape rooms are mainly based on an original idea (87\%), while franchises represent $13 \%{ }^{6}$. Agarwal (2018) and Villar (2018) quantify the weights of dealerships in their respective areas of study at $5 \%$ and $19 \%$, while Spira (2019) quantifies it at $28 \%$ in United States. Our data show a divergence in this respect: some countries have a lower incidence of franchises (e.g. Germany, the Netherlands, etc.), while this model presents a greater weight in others (e.g. Greece, Slovenia, Russia, etc.). Qualitative responses state that franchises are becoming more common but there is no statistical evidence, so the current $13 \%$ should be compared to similar studies in the future.

According to Agarwal (2018), the marketing channels are mainly online, with advertisements on social networks and search engine optimisation being the most frequent forms. Forming mutually beneficial partnerships with other local businesses such as coffee shops, restaurants or even other escape rooms is relatively common. Our data show that most respondents actually enter into some kind of collaboration with the competition (81\%). These working relationships are not exactly inventive, however, consisting of flyers and informal recommendations (60\%). In contrast, more elaborated forms of cooperation can be identified, such as escape routes, escape championships, discount cards and others. In line with Pechlaner, Fisher and Hammann (2008), these kinds of synergies are a source of innovation, generate distinctive products in an inter-organisational network process and are especially relevant for expanding this flourishing market at tourist destinations. These collaborative practices also represent a good example of coopetition, understood as behaviours of same-sector companies that generate a network relationship where cooperation and competition coexist and increase mutual shared-market benefits (Kylanen and Mariani, 2012; Chim-Miki and Batista-Canino, 2017), and being extensible (this network) to whole neighbouring tourist destinations (Żemła, 2016). Corporate clients represent a major percentage of the business for many escape rooms (French and Shaw, 2015; Villar, 2018) and fill the rooms on weekdays, when recreation and tourism might otherwise leave them vacant. Entrepreneurs have found unique venues and forms to expand into (French and Shaw, 2015), such as partnerships with movie studios, games on cruise ships (Royal Caribbean), and street escape rooms.

Some opinions show dissatisfaction with the sector boom, partly in line with Nicholson (2015). According to this author, some proprietors, the first to tap into a small market, began to complain about the headlong rush to open other rooms in the same marketplace, charging lower prices and harming the sector. In addition, as "puzzles" are the key to the business, game challenges are not covered by intellectual property standards and accusations of illicit appropriation are common.

\subsection{Tourism implications}

Based on the methodological premises, tourism appears to play a significant role in the sector: tourists represent $34.8 \%$ of the total demand, with national and international visitors constituting $23.2 \%$ and $11.6 \%$ respectively (see Fig. 3). Despite these data having a fairly high degree of error, other features support the assumption that the number of tourists in the escape room sector is increasing. The scope of the demand shows that the finite nature of the local offer inevitably leads enthusiasts to travel. The offer confirms the relevance of being in a location near a tourist area. Finally, in relation to tourism management, Nagy et al. (2018) highlight the inclusion of escape rooms at great event venues (e.g. the Hungarian Tourism Agency launched a mobile

\footnotetext{
${ }^{6}$ Methodologically: It should be taken into account that franchised companies are less able to respond to the survey due to their commitments to their franchisors.
} 


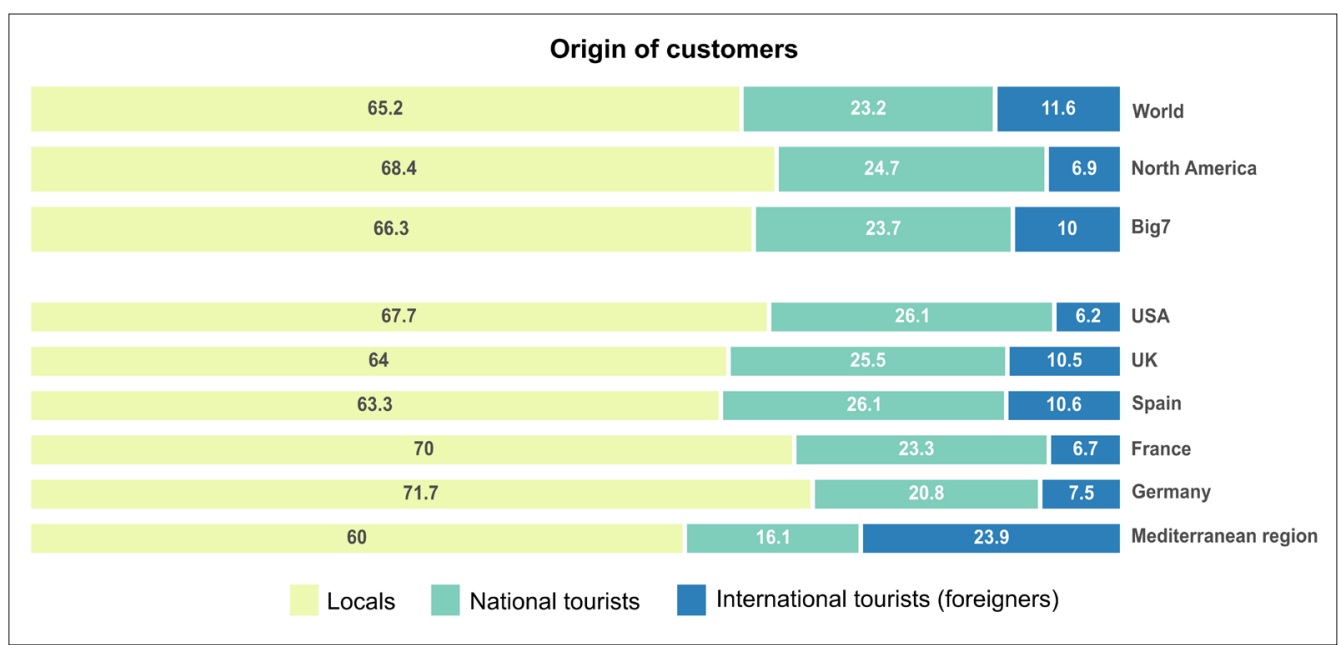

Fig. 3: Tourism implications of escape rooms: place of origin of customers

Source: authors' survey and processing

room at the Sziget Festival) and the organisation of national and international championships (e.g. the Night of Escape Rooms program in Budapest), among others.

According to our tabulation, there is no much difference between the North American and European markets, where tourists represent $31.6 \%$ and $33.7 \%$ of demand, respectively. Some countries and regions stand out, such as Southern Europe (40\%) and particularly Spain (36.7\%). The weight of foreign customers is greater than the national market in the former, to the extent that escape rooms are usually focused on travellers at certain frequently visited destinations (e.g. Dubrovnik, Rome, Corfu, etc.). This same pattern is also detected in several North American tourist spots (New Orleans, Palm Springs, Colorado Springs, etc.).

According to our data, three kinds of tourists can be identified:

i. those that travel for non-escape room-related reasons (cultural, beach, business, visiting the family, etc.) and take in an escape room as an improvised activity;

ii. those who plan to visit escape rooms on their trips; and

iii. escape room tourists, or people who essentially plan their trips in order to play these games.

The survey shows that $93 \%$ of the offer recognises the existence of this third type, who could be termed escape roomers (travellers whose main motivation is to play escape games). Although the majority of our respondents classify these as rare cases $(57.5 \%)$, more than one third receive a visit from escape roomers habitually (35.5\%) or even weekly (7\%). In line with the collected data and other contributions, escape room tourism is spatially conceived as an urban experience or as a road trip. The former is focused on the cities where the offer is broad enough to play multiple games per day. At a national scale, tourists from other parts of Spain make the most of a weekend, a congress or a vacation to play a room. At a higher level, some customers from Germany, Israel or Russia, where the culture of the room escape is well extended, do not hesitate to visit Barcelona to run a marathon of escapes (Picadero Motel, 2016). The latter is based on a road trip: "In the summer of 2018, a group from Chicago drove from there to St. Louis, then Indianapolis, then Louisville. They played over 20 escape games on their trip" (respondent No. 322).

Entrepreneurs are partially aware of the implications of tourism for the business, so they initiate particular actions to attract foreign visitors. These actions are focused on language ability (website and staff languages) and local promotion (hotels, restaurants and tourist information offices). An important feature of the service for tourism is the proportion of games that can be played in other languages: Websites are not usually translated (54.3\%), especially in the USA (97.3\%) and the UK (95.7\%). This contrasts with Big7 enterprises, where half are translated into at least one other language (in Spain, 3 in every 4 are translated). Regarding staff skills, operators are generally able to host and guide the games in one alternative language $(43.0 \%)$, and even two $(13.8 \%)$ or three $(8.2 \%)$. This is especially prevalent in all countries in Europe where, excluding the UK, 90.8\% of companies offer their services in foreign languages.

In connection with visibility in the tourist area, most escape rooms are promoted in the areas around tourist spots and facilities (86.3\%). A significant $24 \%$ announce themselves at three well-considered sites: accommodation, FandB (Food and Beverage), and tourist information offices. Other responses give additional tourist spots where they advertise, such as tourist attractions, summer camps, music festivals and local stores. Schools, radio stations, and coupon guides are the most preferred sites to attract residents' attention apart from restaurants (visited by both tourists and locals).

Finally, according to the respondent entrepreneurs, the overlapping of the spheres of recreation, tourism and work, inside the rooms has been verified. Thus, the profile is varied: local families ("this game is a great activity for families and sometimes three generations play at the same time": respondent No. 131); mixed groups of locals and tourists ("sometimes we receive groups of students with their pals from abroad": respondent No. 111); work-oriented experiences ("we host corporate colleagues for team-building adventures", respondent No. 266); tourists from other segments ("most of the time it's people that are already around my area for a holiday anyway that book the escape room as one of the activities for their time here": respondent No. 273); and the previously-referred to escape roomers ("I am seeing a burgeoning enthusiast culture both locally, regionally, and nationally ... we have groups that use their vacation to travel around a circuit of cites to play as many escape games as they can along the way": respondent No. 33), among others. Escape-rooming has even been identified as a erious leisure activity: in fact, some enthusiasts in the sector have become professional qualified reviewers or bloggers on forums aimed at such specialised demand. 


\subsection{Geographic drivers}

The relative weight given by an escape room owner to urban location factors is decisive for understanding the extent to which they value the geographic context. When asked about these issues, the highest-rated factors are the price of the premises - leased or owned - and how safe the neighbourhood is (both scored at approximately 4 out of 5). To the contrary, a location in a tourist area, being wellconnected by public transit and having other commercial stores nearby receive lower scores (between 3.1 and 3.3 out of 5). There are significant regional differences in this case. For example, public transit is especially underrated in North America, and parking facilities (for private vehicles) receive a higher score. Looking more closely at the national scale, it can be appreciated that it is in the Mediterranean countries - Portugal, Spain, Italy and Greece - where being located in a tourist area, is more appreciated (3.7-3.8 of 5).

Stasiak (2016) compared the geographical distribution of escape rooms in 10 Polish cities. The neighborhoods in and around the old town centres $(2-2.5 \mathrm{~km}$ from the central point) seemed to be the preferred areas. According to this author, the location factors are the higher influx of both inhabitants and tourists into the centre, accessibility by public transit and the use of representative buildings (capable of offering some kind of atmosphere, with a minor investment). Fourthly, leasing prices received less consideration, as, in Stasiak's words: "running escape rooms is $[\ldots]$ a very lucrative undertaking" $(2016$, p. 36$)$. This final factor strongly contrasts with our findings.

On the other hand, Villar (2018) presents some locational drivers and briefly analyses the current distribution of escape games in several Spanish cities. In line with his results, accessibility and leasing price stand out, with proximity to other businesses a less valued factor. This author also remarks that location might be conditioned by the initial investment: "The humblest companies are usually located in less accessible streets, while franchises and larger projects situate their facilities near avenues as well as pedestrian and tourist areas" (2018, p. 630). In general, the need for premises of a certain size and the limited initial available investment - probably linked to the age of the entrepreneur - drive the activity toward the edges of the historical town centre, where accessibility and leasing prices are moderate. More distant areas offer lower prices and greater opportunities for expansion (new games), but few companies are located on the edges of the city.

The service has also been offered in rural areas: Nagy et al. (2018) report a figure of about one hundred facilities in Hungarian rural settlements despite the low potential demand, with tourism playing a crucial role. This type of escape room could take advantage of unique elements in the countryside. Although it is only an idea put forward in a Seville University Chair ideas contest, a project called Plumbum is based on the recovery of traditional identity industries in Linares (Jaen, Spain), to create a space with business marketing possibilities in the form of a gigantic escape room (See Metropol Parasol, 2020).

\subsection{Theme and place}

In this paper, special attention has been paid to the link between escape rooms and the places where they are located, whether in the city itself or on a wider regional scale. In this regard, a specific theme-i.e., a plot, narrative contextualisation, even the environment and atmosphere -used as the set and the driver of the game becomes a relevant issue for evaluating the degree to which local identity and a place's peculiar character influence these kinds of activities.

For this purpose, an appropriate question seeks to establish the thematic offer of our sample. The respondents have provided over 1,000 answers about the different themes proposed in the corresponding rooms and these have been categorised and grouped for better understanding. As can be observed in Figure 4, most of the room themes can

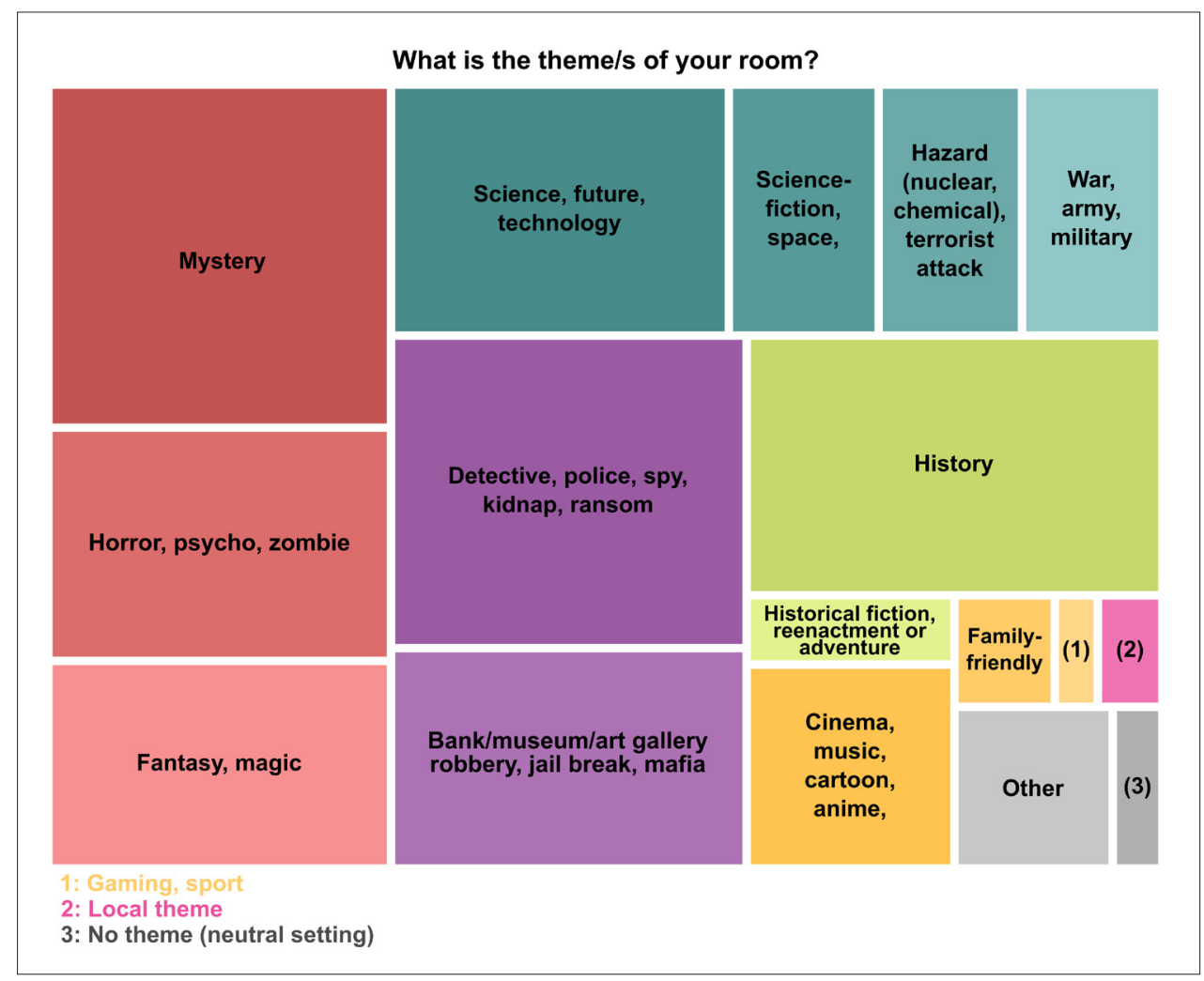

Fig. 4: Themes offered by escape rooms. Source: authors' survey and processing 
be grouped into three main thematic families. The first comprises anything concerning mystery-fantasy-horror and represents almost one-third of the entire sample. The second consists of science and science-fiction arguments, as well as related subjects such as technology, space, nuclear/chemical hazards, terrorist attacks, war and the military, etc. ( $22 \%$ of the sample). The third comprises police and crime topics, including detectives, secret agents, robberies, prisons, the mafia and other similar subjects, and also amounts to almost $22 \%$ of all the answers.

Historical motifs also have a less prominent but still significant weight in the survey, as do those inspired by cultural expressions (the cinema, music, literature, etc.). Only a very small percentage of responses, however, took local themes as their inspiration. This does not mean that the previously mentioned themes are not necessarily linked to local attributes or features (such as, for example, solving a robbery at the Louvre museum in Paris). It seems clear, nonetheless, that not many of the survey respondents explicitly see this resource as a potential way to position their business.

For a better understanding of this phenomenon, other questions delved more deeply into the role of local features and attributes. A very explicit question explores the existence of links between the room theme and the city or region. Approximately three out of every four respondents replied negatively. We also proposed a subjective assessment of the relevance of this particular link (to be responded to on a 1 to 5 Likert scale: see Fig. 5). In general, the results point to the same idea: most of the answers show low-medium values with a mean score of 2.4 out of 5 and a standard deviation of 1.27 . These statistics do vary, however, depending on regional and national particularities. Respondents from Canada and the USA are among the owners who place less importance on the theme-place link (score of approximately 2 and a high standard deviation of 1.25). Most of the participants from other countries give very moderate assessments of between 2.2 and 2.5. Only a small number of respondents (from a minority of countries) award a score above the intermediate value of 3, including the Czech Republic (3.13), Bulgaria (3.71) and India (4.5).

In addition, these minority countries show a lower spread of the score, with their standard deviation generally not exceeding a value of 1 . The cases of Bulgaria and India are quite relevant, with participants giving a higher relative importance to the theme-place issue, revealing even greater agreement with the statement (standard deviation below 0.9 ). Consequently, this group of entrepreneurs tends to have a more homogeneous perspective than in other countries such as Canada and the USA, where responses indicate larger discrepancies and differences in this particular business.

Finally, to underline this idea even further, a question was included about live outdoor rooms (street games). A full half of all respondents state that they do not offer any kind of outdoor experience whatsoever. At the other extreme, one in four respondents state that they do. Finally, a further $25 \%$ of participants state that they might seriously consider doing so, although they do not currently offer any live outdoor games.

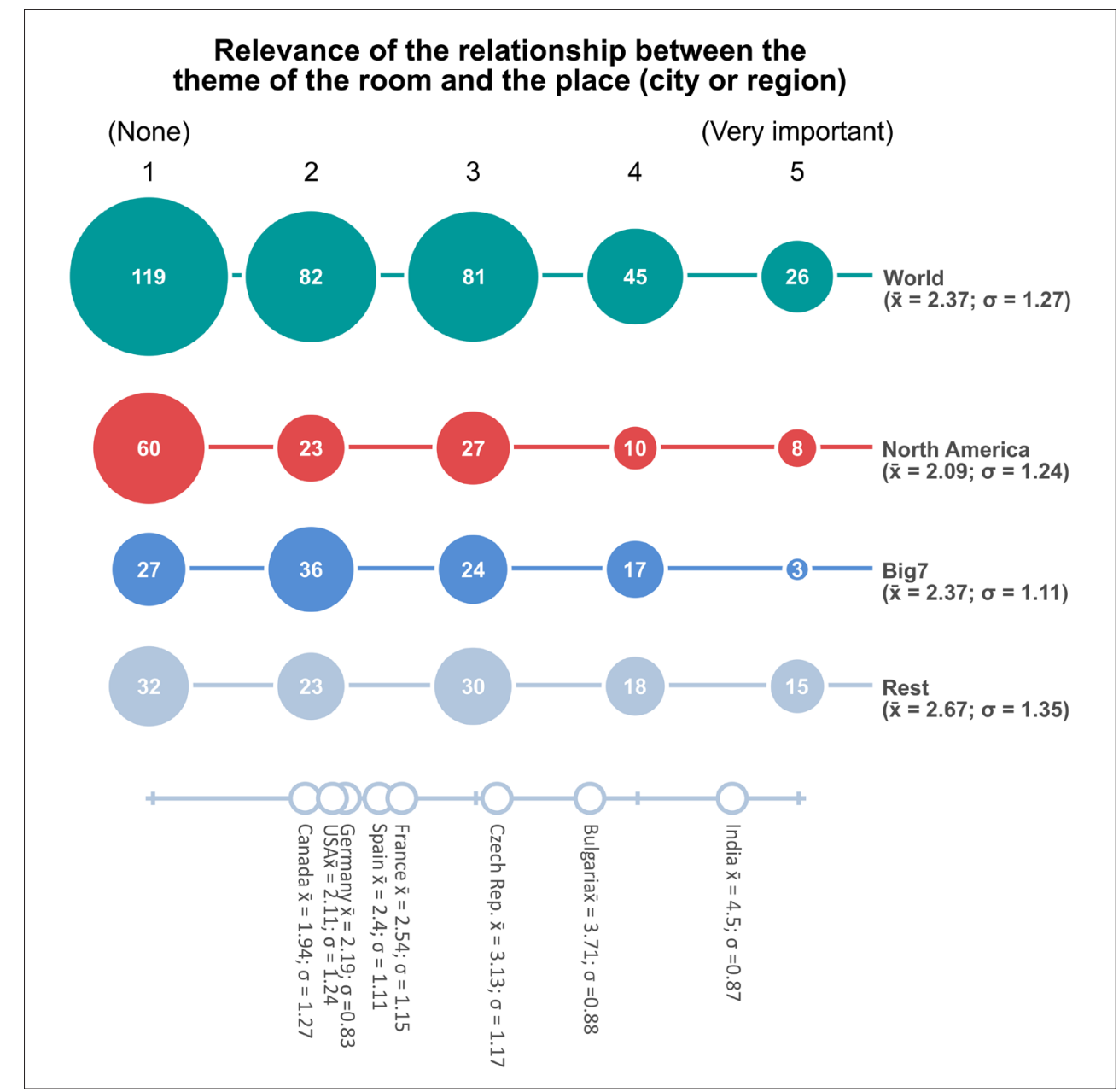

Fig. 5: Relevance of room theme and place (Note: Both the size of the circles and the digit inside represent the number of respondents). Source: authors' survey and processing 
An interesting debate about the role of so-called geographic or territorial capital in the design of a localised (i.e. with its roots in a specific geographic space) leisure experience lies behind these responses. As far as activities with a certain tourist focus (and, therefore, also oriented toward a foreign consumer) are concerned, the elements and attributes that characterise the place, whether on a local or regional scale, can be found to form part of the story that underpins the entire tourist experience. Reading these results, however, shows that the tourist relevance of escape rooms as a leisure experience is still in its fledgling stages. In cases where there is a much clearer tourist vocation, the visiting tourist is taken into account much more, but without forgetting that the main demand is still domestic in origin.

There are, therefore, two very distinct models from this point-of-view. The first and more prevalent of the two is characterised by the fact that this is an "atopical" business (i.e. unrelated to place), with arguments that have no links to the territory and with topics that are global, however localised the spaces and times that they refer to (the crypt of the pharaoh, the pirates of the Caribbean, the Wild West, etc.) or ubiquitous (zombies, steampunk, detectives solving a crime, etc.). Be that as it may, these types of escape games correspond to the cultural dynamics of late modernity in the context of global capitalism that Disneyfies leisure experiences (Sorkin, 1992; Beardsworth and Bryman, 1999). Such an intended theming of an escape room responds to a mechanism that attempts to make it distinctive, but much of this attempt trivialises a topic (spaces-times-objects-people) in a context marked by increasingly frequent homogenous and standardised cultural narratives.

The second model, however, takes into account the peculiarities and specificities of place and this connects the leisure supply with the strategies of the tourism industry, in which attributes, authenticity, heritage and local identity form part of the product's design and storyline. In these cases, the experience might benefit from dual comparative advantages: local consumers can take part in the escape as a social practice rather than identity self-representation, whereas non-local tourists can find in the escape room another tourist offering through which to learn about, explore and actively experience the destination. Some entrepreneurs have understood the opportunities that this business model offers, with local heritage playing a significant role as the main mediator of the gaming experience. This is clear from the testimony of one escape room owner in Norwich (United Kingdom), who expresses it in similar terms:

"At History Mystery, our focus is on interpreting heritage through escape gaming. We work with historic places and museums to develop games that tell real stories from history in the places that they happened. We believe that there is a huge untapped demand for using escape gaming as a way of engaging with other areas of tourism, especially heritage tourism" (respondent No. 4).

Whatever the case, not even this second model is devoid of the risk that this theming process might end up being a simplistic and contrived exercise of autochthonous qualities - which always leads us to the prickly subject of the authenticity of the touristic experience (Cousin, 2011; Piazzoni, 2018; Rickly, 2018).

\section{Conclusions and future research}

First and foremost, this research project has enabled the mapping and quantification of the global distribution of escape rooms as a new form of leisure. They first emerged as a leisure product in a small number of cities at the beginning of the 2010 s, but their number has grown exponentially over the last few years (2015-2019 period) and spread out from the main urban areas to the rest of the territory in various regions in the world. In this respect, limitations have been observed in escape room repositories (which are used as a data source for this study), especially regarding the limited amount of information about East Asia, which provides an interesting opportunity for the future.

The emergence of this phenomenon could be linked to the value of analogical and off-line experiences in a world that is increasingly virtual - to the point that it could be understood to be a reaction to digital saturation. One key question for the future is to determine whether escape rooms are an ephemeral response or whether they will become a consolidated part of the leisure industry. The business' main weakness - that it sells a single-use experience: once users have played the game in a given room, they do not become long-term customers - means that they have to reinvent themselves every so often, with the consequent required investment. Bearing in mind the characteristics of the sector - small, flexible businesses led by young entrepreneurs and shaped by demand - the coopetition and idea-sharing strategy and even the swapping of entire games, may be crucial for securing the industry's mediumand long-term future. The proliferation of new rooms and the lack of administrative control, however, mean that copyrighting is one of the entrepreneurs' main concerns. It is, therefore, necessary to investigate whether the public apparatus recognises the sector across its entire spectrum (official company directories, registering of patents, social and tourism promotion, etc.) and whether the sector sees this as interference or as an opportunity.

This study has also demonstrated the importance of tourism for the business' survival. In fact, it has revealed the existence of a new tourist segment, the escape roomers. Within this collective, the influencers stand out. These are people who recount their experiences on their sites and generate a qualified opinion. In this way, some of the demand is turned into an additional actor on the industry's social map. Escape tourism should, therefore, be acknowledged in destinations' promotion strategies. In this respect, the analysis of User Generated Content using netnography techniques could help us to understand the relationship between the entrepreneur and the demand in general and the influencers in particular, and its inferences for tourist behaviours.

Escape rooms seem to be aligned with the current discourse on local tourism promotion and management. Several reasons are suggested: first, because the experience has become consolidated as a promotional strategy for destinations; second, because (given their location patterns) they expand and decongest tourist areas; and third, because they shed light on creative tourism, which creates a contact between a local person (gamemaster) and a visitor (player) through the originality of a discourse (topic). With respect to the latter, however, this article reveals the still weak coherence between escape rooms and local culture and their tourist ecosystem. Aligning topics with the local or regional context would mean that entrepreneurs do not have to continue trivialising the destination's image any longer, and that they can not only generate a discourse connected to what is 'real' but are able to reverse its trivialisation and refashion it. 


\section{Acknowledgements}

This work has been supported by the National Program for Fundamental Research Projects, in the project: "Inteligencia territorial versus crecimiento turistico. La planificacion y gestion de destinos ante el nuevo ciclo expansivo inmobiliario" [Territorial intelligence versus tourist growth. The planning and management of destinations before the new real estate expansion cycle] (Ref. PGC2018-095992-B-I00) financed by the Spanish Government's Ministry of Science, Innovation and Universities.

\section{References:}

AGARWAL, P. (2018): SEO ORB. State of the Escape Room Industry - Report 2018, Owner's Survey [online]. [cit 03.03.2020]. Available at: https://seoorb.com/survey-2018

BARDIN, L. (1977): L'analyse de contenu. Paris, Presses Universitaires de France.

BARTLETT, K., ANDERSON, J. (2019): Using an Escape Room to Support the Learning of Science Content. In: Graziano K. [ed.]: Proceedings of Society for Information Technology and Teacher Education International Conference (pp. 710-715). Las Vegas (NV) United States, Association for the Advancement of Computing in Education (AACE) [online]. [cit. 11.11.2019]. Available at: https://www.learntechlib.org/primary/p/207719/

BAKHSHESHI, F. F. (2019): Escape Rooms: A New phenomenon in Tourism. In: 2019 International Serious Games Symposium (pp. 38-41). New York, Institute of Electrical and Electronics Engineers.

BAKHSHESHI, F. F., GAZHIANI, G. (2019): Tourism Based Games: A Study of Challenges and Profits. In: 2019 International Serious Games Symposium (pp. 30-37). New York, Institute of Electrical and Electronics Engineers.

BASS, D. (2020): Escape Room Owners Solve the Pandemic Puzzle [online]. Bloomberg Businessweek [cit. 25.08.2020] Available at: https://www.bloombergquint. $\mathrm{com} /$ businessweek/escape-rooms-are-planning-theirsurvival-during-coronavirus

BEARDSWORTH, A., BRYMAN, A. (1999): Late modernity and the dynamics of quasification: the case of the themed restaurant. The Sociological Review, 47(2): 228-257.

BORREGO, C., FERNÁNDEZ, C., BLANES, I., ROBLES, S. (2017): Room escape at class: Escape games activities to facilitate the motivation and learning in computer science. JOTSE, 7(2): 162-171.

CARTIER, C. (2005): Introduction. Touristed landscapes/ seductions of place. In: Cartier, C., Lew, L. [eds.]: Seductions of Place. Geographical perspectives on globalization and touristed landscapes (pp. 16-31). London and New York, Routledge.

CHIM-MIKI, A. F., BATISTA-CANINO, R. M. (2017): Tourism coopetition: An introduction to the subject and a research agenda. International Business Review, 26(6): 1208-1217.

CHINAEGA (2020): About China EGA Escape Room Industry Alliance [cit.11.09.2020]. Available at: https:// www.chinaega.com/archives/192

COOK, P. S. (2010): Constructions and experiences of authenticity in medial tourism: The performances of places, spaces, practices, objects and bodies. Tourist Studies, 10(1): 135-153.

COUSIN, S. (2011): Authenticité et tourisme. Les Cahiers du Musée des Confluences. Revue Thématique, 8: 59-66.

CROUCH, D. (2013): Space and place-making: Space, culture and tourism. In: Smith, M., Richards, G. [eds.]: The Routledge Handbook of Cultural Tourism (pp. 247-251). London and New York, Routledge.

CSIKSZENTMIHALYI, M. (1990): Flow: The psychology of optimal experience. New York, Harper and Row.

DIETRICH, N. (2018): Escape Classroom: The Leblanc Process-An Educational "Escape Game". Journal of Chemical Education, 95(6): 996-999.

DILEK, S. E., DILEK, N. K. (2018): Real-life escape rooms as a new recreational attraction: The case of Turkey. Anatolia, 29(4): 495-506.

DORADO, G. (2018): Escape rooms from a collaborative and interdisciplinary perspective. Encuentro: Revista de investigación e innovación en la clase de idiomas, 27: 22-37.

ELLIS, G. D., FREEMAN, P. A., JAMAL, T., JIANG, J. (2019): A theory of structured experience. Annals of Leisure Research, 22(1): 97-118.

FRENCH, S., SHAW, J. (2015): The unbelievably lucrative business of escape rooms [online]. [cit. 08.07.2020]. Available at: https://www.marketwatch.com/story/theweird-new-world-of-escape-room-businesses-2015-07-20

GUNN, H. (2002): Web-based surveys: Changing the survey process. First Monday, 7(12).

HALL, C. M., PAGE, S. J. (2014): The geography of tourism and recreation: Environment, place and space. Abingdon, Routledge.

JEFFRIES, A. (2013): In China, people are paying $\$ 13$ to be locked in a room and forced to solve puzzles to get out. The Verge [online]. [cit. 04.04.2010]. Available at: https:// www.theverge.com/2013/12/18/5223340/china-escaperoom-games

KIM, H., JAMAL, T. (2007): Touristic quest for existential authenticity. Annals of Tourism Research, 34(1): 181-201.

KINIO, A., DUFRESNE, L., BRANDYS, T., JETTY, P. (2017): Break out of the classroom: The use of escape rooms as an alternative learning strategy for surgical education. Journal of Vascular Surgery, 66(3): e76.

KOLAR, T. (2017): Conceptualising tourist experiences with new attractions: the case of escape rooms. International Journal of Contemporary Hospitality Management, 29(5): 1322-1339.

KOLAR, T., ČATER, B. (2018): Managing group flow experiences in escape rooms. International Journal of Contemporary Hospitality Management, 30(7): 2637-2661.

KOWALIK, A. (2015): Ucieczka do pieniędzy. Forbes Poland [online]. [cit. 22.03.2020]. Available at: https://www. forbes.pl/pierwszy-milion/escape-roomy-podbijajapolske/661rybg

KRIPPENDORFF, K. (1980): Content analysis: An introduction to its methodology ( $3^{\text {rd }}$ ed.). Thousand Oaks (CA), Sage.

KYLANEN, M., MARIANI, M. M. (2012): Unpacking the temporal dimension of coopetition in tourism destinations: Evidence from Finnish and Italian theme parks. Anatolia, 23(1): 61-74. 
LAU, R. (2010): Revisiting authenticity: a social realist approach. Annals of Tourism Research, 37(2): 478-498.

MELO, M., JOHNSON, A. (2018): Teaching technical writing through designing and running escape rooms. Dialogue: Interdisciplinary Journal of Popular Culture and Pedagogy, 5(2): 1-13.

METROPOL PARASOL (2020): La puesta en valor del canal seco de la Expo, gana el IV Concurso de Ideas de la Cátedra Metropol-Parasol de la Universidad de Sevilla [online]. [cit. 20.06.2020]. Available at: https://catedrametropol. com/wp-content/uploads/2018/03/PLUMBUM_01-baja.jpg

MESZAROS, M. L. (2020): Can Virtual Escape Rooms Save the Genre? [online]. CBR.com [cit. 25.09.2020]. Available at: https://www.cbr.com/virtual-escape-rooms-can-save-genre/

MITAS, O., BASTIAANSEN, M. (2018): Novelty: A mechanism of tourists' enjoyment. Annals of Tourism Research, 72: 98-108.

NAGY, A., PETYKÓ C., KISS D. D., EGEDY T. (2018): Kreatív turizmus Budapesten - Szabadulószobák az innovatív turisztikai piacon. Turizmus Bulletin, XVIII (4): $30-40$

NICHOLSON, S. (2015): Peeking behind the locked door: A survey of escape room facilities. Available at: http:// scottnicholson.com/pubs/erfacwhite.pdf

NICHOLSON, S. (2018): Creating engaging escape rooms for the classroom. Childhood Education, 94(1): 44-49.

PAKHALOV, A., ROZHKOVA, N. (2020): Escape rooms as tourist attractions: Enhancing visitors' experience through new technologies. Journal of Tourism, Heritage and Services Marketing, 6(2): 55-60.

PECHLANER, H., FISCHER, E., HAMMANN, E. M. (2006) Leadership and innovation processes-development of products and services based on core competencies. Journal of Quality Assurance in Hospitality and Tourism, 6(3-4): 31-57.

PIAZZONI, M. F. (2018): The Real Fake Authenticity and the Production of Space. New York, Fordham University Press.

PICADERO MOTEL BLOG (2016): Turismo de Room Escape [online]. [cit.16.03.2020]. Available at: https:// www.picaderomotel.com/blog/turismo-de-room-escape/

PINE, B., GILMORE J. H. (1999): The experience Economy: Work is theatre and every business a Stage. Harvard, Harvard Business Press.

PRITCHARD, A., MORGAN, N. J. (2001): Culture, identity and tourism representation: marketing Cymru or Wales? Tourism Management, 22(2): 167-179.

RICHARDS, G. (2009): Creative tourism and local development. In: Wurzburguer, R., Pattakos, A., Pratt. S. [eds.]: Creative Tourism: A global conversation (pp. 7890). Santa Fe, Sunstone.

RICKLY, J. M. (2013): Existential Authenticity: Place Matters. Tourism Geographies, 15(4): 680-686.
RICKLY, J. M., MCCABE, S. (2017): Authenticity for tourism design and experience. In: Fesenmaier, D. and Xiang Z. [eds.]: Design science in tourism (pp. 55-68). Cham, Springer.

RICKLY, J. M. (2018): Tourism geographies and the place of authenticity. Tourism Geographies, 20(4): 733-736.

ROE, M. (2020): Coronavirus Shut Down Popular Escape Rooms. Now The Industry Is Going Virtual [online]. LAist [cit. 25.09.2020]. Available at: https:/laist. com/2020/05/21/escape-rooms-coronavirus-covid-19virtual-online.php

SCHREIER, M. (2012): Qualitative Content Analysis in Practice. London, Sage.

SOFMARR LLC (2018): Escape the Roomz. Escape Room Business Directory [online]. Available (on demand) at: https://escapetheroomz.com/escape-room-directory/

SOLOMON, D. J. (2001): Conducting web-based surveys. Practical assessment research and evaluation, 7(19) [online]. [cit 12.03.20120]. Available at: http:/ PAREonline.net/getvn.asp? $\mathrm{v}=7$ and $=19$

SORKIN, M. (1992): Variations on a theme park: The new American city and the end of public space. New York, Hill and Wang.

SPIRA, L. (2019): July 2018 Escape Room Industry Growth Study. Available at: https://roomescapeartist. com/2018/07/28/2018-escape-room-industry/

STASIAK, A. (2016): Escape rooms: A new offer in the recreation sector in Poland. Turyzm/Tourism, 26(1): 31-47.

STASIAK, A. (2019): Escape Rooms in Poland: A DemandLed Approach Using 'Netnographic' Research. Turyzm/ Tourism, 29(1): 71-82.

TRUONG， T. L. H.，LENGLET， F.，MOTHE，C. (2018): Destination distinctiveness: Concept, measurement, and impact on tourist satisfaction. Journal of Destination Marketing and Management, 8: 214-231.

VILLAR, A. (2018): Ocio y turismo millennial: El fenómeno de las salas de escape. Cuadernos de Turismo, 41: 615-636.

WANG, N. (1999): Rethinking authenticity in tourism experience. Annals of Tourism Research, 26: 349-370.

WEBER, R. P. (1990): Basic content analysis (2 ${ }^{\text {nd }}$ ed.). Newbury Park, London, New Delhi, Sage.

WISE, H., LOWE, J., HILL, A., BARNETT, L., BARTON, C. (2018): Escape the welcome cliché: Designing educational escape rooms to enhance students' learning experience. Journal of Information Literacy, 12(1): 86-96.

WÓJCIK-AUGUSTYNIAK, M., MULTAN， E. (2020): Evaluation of escape room competitive position in Polish macro regions with $2 \mathrm{~d}$ and $1 \mathrm{~d}$ strategic group maps. Entrepreneurship and Sustainability Issues, 7(3): 16321652.

ŻEMŁA, M. (2016): Tourism destination: The networking approach. Moravian Geographical Reports, 24(4): 2-14. 


\begin{tabular}{|c|c|c|c|c|c|c|c|}
\hline Country & $\begin{array}{c}\text { ER } \\
\text { Companies } \\
\text { (The Escape } \\
\text { Roomz) }\end{array}$ & $\begin{array}{l}\text { Population } \\
\text { (thousands) } \\
\quad(2018)\end{array}$ & IER & Country & $\begin{array}{c}\text { ER } \\
\text { Companies } \\
\text { (The Escape } \\
\text { Roomz) }\end{array}$ & $\begin{array}{c}\text { Population } \\
\text { (thousands) } \\
\quad(2018)\end{array}$ & IER \\
\hline United States & 2,155 & 327,167 & 6.59 & Thailand & 10 & 69,429 & 0.14 \\
\hline Spain & 460 & 46,724 & 9.85 & United Arab Emirates & 9 & 9,631 & 0.93 \\
\hline United Kingdom & 288 & 66,489 & 4.33 & Saudi Arabia & 8 & 33,700 & 0.24 \\
\hline Netherlands & 280 & 17,231 & 16.25 & Singapore & 8 & 5,639 & 1.42 \\
\hline Canada & 271 & 37,059 & 7.31 & Viet Nam & 8 & 95,540 & 0.08 \\
\hline Germany & 266 & 82,928 & 3.21 & Kuwait & 7 & 4,137 & 1.69 \\
\hline France & 256 & 66,987 & 3.82 & Peru & 7 & 31,989 & 0.22 \\
\hline Italy & 241 & 60,431 & 3.99 & Serbia & 7 & 6,982 & 1.00 \\
\hline Poland & 223 & 37,979 & 5.87 & Jordan & 6 & 9,956 & 0.60 \\
\hline Greece & 83 & 10,728 & 7.74 & Lebanon & 6 & 6,849 & 0.88 \\
\hline Australia & 74 & 24,992 & 2.96 & Japan & 5 & 126,529 & 0.04 \\
\hline Belgium & 65 & 11,422 & 5.69 & Luxembourg & 5 & 608 & 8.23 \\
\hline Romania & 60 & 19,474 & 3.08 & Nigeria & 5 & 195,875 & 0.03 \\
\hline Switzerland & 59 & 8,517 & 6.93 & Panama & 5 & 4,177 & 1.20 \\
\hline Israel & 57 & 8,884 & 6.42 & Colombia & 4 & 49,649 & 0.08 \\
\hline India & 56 & $1,352,617$ & 0.04 & Hong Kong & 4 & 7,451 & 0.54 \\
\hline Finland & 55 & 5,518 & 9.97 & Taiwan & 4 & 23,577 & 0.17 \\
\hline Czech Republic & 52 & 10,626 & 4.89 & Chile & 3 & 18,729 & 0.16 \\
\hline Portugal & 34 & 10,282 & 3.31 & Costa Rica & 3 & 4,999 & 0.60 \\
\hline Bulgaria & 33 & 7,024 & 4.70 & Andorra & 3 & 77 & 38.96 \\
\hline Austria & 33 & 8,847 & 3.73 & Algeria & 2 & 42,228 & 0.05 \\
\hline Mexico & 33 & 126,191 & 0.26 & Azerbaijan & 2 & 9,942 & 0.20 \\
\hline Malaysia & 28 & 31,529 & 0.89 & Bahrain & 2 & 1,569 & 1.27 \\
\hline Turkey & 28 & 82,320 & 0.34 & Bosnia \& Herzegovina & 2 & 3,324 & 0.60 \\
\hline New Zealand & 26 & 4,886 & 5.32 & Bolivia & 2 & 11,353 & 0.18 \\
\hline Hungary & 25 & 9,769 & 2.56 & Burma & 2 & 53,708 & 0.04 \\
\hline Norway & 22 & 5,314 & 4.14 & Brunei & 2 & 429 & 4.66 \\
\hline Brazil & 21 & 209,469 & 0.10 & Cambodia & 2 & 16,250 & 0.12 \\
\hline Sweden & 21 & 10,183 & 2.06 & Sri Lanka & 2 & 21,670 & 0.09 \\
\hline Ireland & 19 & 4,854 & 3.91 & Ecuador & 2 & 17,084 & 0.12 \\
\hline Ukraine & 18 & 44,623 & 0.40 & El Salvador & 2 & 6,421 & 0.31 \\
\hline Croatia & 16 & 4,089 & 3.91 & Georgia & 2 & 3,731 & 0.54 \\
\hline Russia & 16 & 144,478 & 0.11 & Iran & 2 & 81,800 & 0.02 \\
\hline Denmark & 15 & 5,797 & 2.59 & Kazakhstan & 2 & 18,276 & 0.11 \\
\hline Egypt & 15 & 98,424 & 0.15 & North Macedonia & 2 & 2,083 & 0.96 \\
\hline South Korea & 15 & 51,635 & 0.29 & Morocco & 2 & 36,029 & 0.06 \\
\hline Indonesia & 15 & 267,663 & 0.06 & Malta & 2 & 484 & 4.14 \\
\hline Slovakia & 14 & 5,447 & 2.57 & Montenegro & 2 & 622 & 3.21 \\
\hline Slovenia & 14 & 2,067 & 6.77 & Pakistan & 2 & 212,215 & 0.01 \\
\hline Argentina & 13 & 44,495 & 0.29 & Qatar & 2 & 2,782 & 0.72 \\
\hline Estonia & 13 & 1,321 & 9.84 & Reunion & 2 & 867 & 2.31 \\
\hline Lithuania & 13 & 2,790 & 4.66 & Puerto Rico & 2 & 3,195 & 0.63 \\
\hline Philippines & 13 & 106,652 & 0.12 & Tunisia & 2 & 11,565 & 0.17 \\
\hline Latvia & 12 & 1,927 & 6.23 & Uruguay & 2 & 3,449 & 0.58 \\
\hline Cyprus & 11 & 1,189 & 9.25 & 23 other countries & 23 & 368,925 & 0.06 \\
\hline
\end{tabular}

Appendix 1: Global distribution of escape rooms and popularity index (IER)

Source: authors' composition from Sofmarr LLC (2018) 